\title{
Prevalence of morbid jealousy among inpatients in a psychiatry unit in Sri Lanka
}

\author{
Chaya Kapugama, Chathurie Suraweera, Wajantha Kotalawala, Vipula Wijesiri, \\ Maneesha Dalpatadu, Raveen Hanwella
}

\section{Background}

Morbid jealousy includes a range of irrational thoughts and emotions, with associated unacceptable and abnormal behaviour. Common forms of psychopathology are delusions, obsessions and overvalued ideas.

Aims

Todeterminetheprevalenceofmorbidjealousyin psychiatric inpatients, describe the different phenomenological forms, and range of associated behaviours.

Methods

All inpatients treated at University Psychiatry Unit, NHSL during a three month period were examined. Those who had 'morbid jealousy' were evaluated regarding psychopathology, emotions and associated behaviours. Results

Of 145 patients admitted during the study period, 76 were in a intimate relationship. Of these, 35 (46.05\%) were male.
Mean age was males 49.6 years, females 42.72 years. Commonest diagnoses were schizophrenia (22.36\%), unipolar depression (19.73\%), alcohol problems (17.10\%), and bipolar mania (15.78\%). Morbid jealousy was identified in 13 (9 male, 4 female). Overall prevalence was $17.10 \%$ (95\% Cl 8.64\%-25.56\%). The psychopathology of morbid jealousy was overvalued ideas ( $n=7,53.84 \%)$, delusions of jealousy ( $n=4,30.76 \%)$ and obsessional $(n=2,15.38 \%)$. Associated behaviours included verbal accusations $(n=13)$, interrogations $(n=12)$, checking $(n=11)$, stalking $(n=5)$, threats/ acts of violence $(n=8)$, increased demands for sex $(n=4)$ and excessive demonstration of love $(n=2)$.

Conclusions

The prevalence of morbid jealousy is high in psychiatry inpatients in Sri Lanka.

SL J Psychiatry 2013; 4 (2):38-40

\section{Introduction}

Morbid jealousy has captured the interest of many in the field of psychiatry with a wide range of literature available on the subject, most notable and comprehensive being that by Shepherd (1). It has been defined in various ways and the nomenclature is confusing. The wider definition refers to jealousy in couple relationships which lead to distress in one or both partners, and causes a disruption of the relationship (3).

In morbid jealousy, the psychopathology is primarily the preoccupation with a partner's sexual infidelity. This preoccupation can be a delusion, obsession or an overvalued idea (4). The distinction between these forms is sometimes difficult but important as it has implications in management (5). Clinical features consist of a range of irrational thoughts and emotions, and associated unacceptable or abnormal behaviours $(6$, $7)$. The jealous person and more so his partner, suffer immense distress due to the behaviours associated with the jealousy. These behaviours range from stalking the partner, restricting the partner's life, physical violence to even killing the partner. The behaviours are different in males and females (8). A positive role of jealousy has also been described where it is seen as a sign of love and caring (6).

A study of hospitalized patients reported a prevalence of $1.1 \%$ in delusional jealousy. In the same study delusional jealousy was most frequent seen in 'organic psychoses' and least in affective disorders (9). The organic aetiology of morbid jealousy has been recognised widely. A series of five cases describe patients with conditions such as cerebral infarcts, head injury following road traffic accident and meningioma, who developed morbid jealousy (10). Morbid jealousy is also associated with dementia (11).

Morbid jealousy holds a prominent place in literature and has been used by novelists and dramatists ranging from Shakespeare to Kalki. The classic example in literature is that of Othello, who kills his wife Desdemona and commits suicide as a result of his morbid jealousy (12).

Culture plays a role in the expression and clinical manifestations of morbid jealousy. A series of cases from Sri Lanka show that the prevalence is equal in males and females (2). There is very little data on the prevalence of morbid jealousy in different settings in Sri Lanka and the cultural aspects of this phenomenon have not been explored in depth. The aim of this study was to establish the prevalence of morbid jealousy among in-patients in a psychiatry unit.

\section{Method}

This is a descriptive cross sectional study which included all the inpatients admitted to the University Psychiatry Unit, National Hospital of Sri Lanka during a three month period from October 2012 to January 2013. The University Psychiatry Unit consists of an inpatient, liaison, out patient and day units (14). Compared to out patients who are mostly in remission, inward patients are admitted due to acute exacerbation of the illness (14). 
'Morbid jealousy' was defined as jealousy that causes distress in the jealous person and/or the target person and disrupts the functioning of one or both of them and disrupts the relationship. A detailed clinical interview was conducted by the authors using a semi structured questionnaire to identify morbid jealousy. The questionnaire was based on the behaviours, emotions and thinking described in literature $(1,6)$. Where possible, partners of the patients were also interviewed if both the patient and partner consented. Diagnosis of the primary illness was made according to ICD 10 clinical criteria (13).

Ethical clearance was obtained from the Ethics Review Committee of National Hospital of Sri Lanka. Informed consent was obtained from all patients who participated in the study.

\section{Results}

There were 145 inpatients admitted during the study period to the University Psychiatry Unit. Seventy six were in an intimate relationship currently (spouse or partner). Of these, $46.05 \%$ were males. Mean age was males 49.6 years, females 42.72 years. The diagnoses is given in table 1 .

Thirteen patients had morbid jealousy ( 9 men, 4 women). The overall prevalence rate was $17.10 \%$ (95\% CI $8.64 \%-25.56 \%)$. The mean age of patients with morbid jealousy was 39.53 years. There was one patient aged 70 years. The psychopathology of morbid jealousy was overvalued ideas $(n=7,53.84 \%)$, delusions of jealousy $(n=4,30.76 \%)$ and obsessional $(\mathrm{n}=2,15.38 \%)$.

\begin{tabular}{|l|l|l|l|l|}
\hline \multicolumn{4}{|l|}{ Table 1. Description of sample } & \\
\hline & $\begin{array}{l}\text { Male } \\
n(\%)\end{array}$ & $\begin{array}{l}\text { Female } \\
n(\%)\end{array}$ & $\begin{array}{l}\text { Total } \\
n(\%)\end{array}$ & $\begin{array}{l}\text { Duration } \\
\text { of illness } \\
\text { years }\end{array}$ \\
\hline $\begin{array}{l}\text { Age years } \\
\text { (mean) }\end{array}$ & 49.6 & 42.72 & & \\
\hline Gender & $\begin{array}{l}35 \\
(46.05)\end{array}$ & $\begin{array}{l}41 \\
(53.94)\end{array}$ & $76(100)$ & \\
\hline Schizophrenia & $6(17.1)$ & $11(26.8)$ & $17(22.4)$ & 7.8 \\
\hline $\begin{array}{l}\text { Unipolar } \\
\text { depression }\end{array}$ & $6(17.1)$ & $9(22.0)$ & $15(19.7)$ & 4.1 \\
\hline $\begin{array}{l}\text { Alcohol } \\
\text { problems }\end{array}$ & $13(37.1)$ & - & $13(7.1)$ & 6.3 \\
\hline Bipolar mania & $5(14.3)$ & $7(17.1)$ & $12(15.8)$ & 13.8 \\
\hline Dementia & $1(2.9)$ & $2(4.9)$ & $3(3.9)$ & 2.5 \\
\hline $\begin{array}{l}\text { Bipolar } \\
\text { depresion }\end{array}$ & - & $2(4.9)$ & $2(2.6)$ & 10.3 \\
\hline $\begin{array}{l}\text { Obsessive } \\
\text { compulsive } \\
\text { disorder }\end{array}$ & $2(5.7)$ & $1(2.4)$ & $3(3.9)$ & 8.6 \\
\hline Others & $2(5.7)$ & $9(22.0)$ & $11(14.5)$ & 2.2 \\
\hline
\end{tabular}

Two patients with morbid jealousy had schizophrenia, one had delusional disorder, one was in an acute manic episode, four were diagnosed with depressive disorder, (two of whom were admitted following acts of deliberate self-harm), three had alcohol use disorder (one admitted following deliberate self-harm), one had obsessive compulsive disorder and one had paranoid personality disorder.

All thirteen patients made verbal accusations to their partners; twelve interrogated the partners; eleven had checking behaviours including checking phones $(n=8)$, handbags/ wallets $(n=6)$, other belongings $(n=4)$, clothes and undergarments $(n=2)$. One patient checked his wife's body for tell-tale signs of sexual encounters. Nine patients regularly checked the partners' whereabouts; five stalked the partners or employed other people to follow them.

Eight patients made threats of violence regularly and had engaged in acts of violence, ranging from hitting the partner and throwing objects at the partner. One patient tried to run over the partner using a vehicle. Seven of these were men. Excessive demonstration of love was present in two patients (one male, one female). None were excessively dependent on the partners. Four males made increased demands for sexual activity.

The commonest emotional response to feelings of jealousy was anger $(n=9$, seven men). Six patients reported experiencing fear and five experienced sadness. Three said they had problems in their sexual relationship. Seven men fulfilled criteria for harmful use or alcohol dependence. One each used cannabis, cigarettes and diazepam.

\section{Discussion}

In this study the prevalence of morbid jealousy of inpatients was $17.10 \%$. Their psychiatric diagnoses were variable. Verbal accusations, interrogation of the partner, various checking behaviours, threats and acts of violence were the common associated behaviours.

The prevalence of morbid jealousy in this study was much higher than in a similar study carried out in Munich (9). The behaviours associated with morbid jealousy were similar to those described in a case series from Colombo (2) and also to a community study conducted in Dunedin (8).

Several factors may have contributed to the high prevalence in this sample. This study included morbid jealousy in three different forms of psychopathology, namely, delusions of infidelity, overvalued ideas and obsessions. The majority of the patients had overvalued ideas $(53.84 \%)$. Information from patients' partners may have helped to identify a few hidden cases where the patients did not admit to having features of morbid jealousy. The small sample size resulted in a wide confidence interval.

However it is possible that the actual prevalence in Sri Lanka is higher than in Western countries. Certainly 
this is worth exploring further. The high prevalence of morbid jealousy among psychiatric inpatients, maybe a reflection of the high prevalence in the community. Since there is no data on community prevalence of morbid jealousy in Sri Lanka, further studies are needed to understand this phenomenon. The extent of behaviours accepted as normal by the family and the partners' reaction to such behaviours also need consideration.

This study throws light on the pressing need of exploring this phenomenon further in Sri Lanka since the distress endured by patients and their partners may be much higher than acknowledged. Psychiatrist need to focus on identifying and managing such persons.

\section{Declaration of interest}

None declared

\section{C.Kapugama, C.Suraweera, W.Kotalawala, V.Wijesiri,}

M.Dalpatadu, R.Hanwella

University Psychiatry Unit, National Hospital of Sri Lanka,

Sri Lanka

Corresponding author: C. Kapugama

E mail: chayakapugama@yahoo.com

\section{References}

1. Shepherd, M. Morbid jealousy: some clinical and social aspects of a psychiatric syndrome. Journal of Mental Science (1961), 107, 687- 753.

2. De Silva D, De Silva P. Morbid jealousy in an Asian country: a clinical exploration from Sri Lanka. International Review of Psychiatry (1999) 11, 116- 121

3. De Silva P, Marks M. Jealousy as a clinical problem: Practical issues of assessment and treatment. Journal of Mental Health (1994) 3, 195-204
4. Kingham M, Gordon H. Aspects of Morbid Jealousy. Advances in Psychiatric Treatment (2004) 10:207-215

5. Batinic B, Duisin D, Barisic J. Obsessive versus Delusional Jealousy. Psychiatr Danub. 2013 Sep; 25(3):334-9.

6. De Silva P. Jealousy in couple relationships: nature, assessment and therapy. Behaviour Research and Therapy, (1997) 35, 973 \pm 985.

7. Tarrier N, Beckett R, Harwood S, Bishay N. Morbid jealousy: a review and cognitive behavioural formulation. British Journal of Psychiatry (1990). 157, 319- 326

8. Mullen P, Martin J.L. Jealousy: a community study. British Journal of Psychiatry (1994). 164, 35- 43.

9. Soyka, M., Naber G., Volcker, A. Prevalence of Delusional Jealousy in Different Psychiatric Disorders: An Analysis of 93 Cases. British Journal of Psychiatry (1991), 158, 549-553

10. Kuruppuarachchi KA, Seneviratne AN. Organic Causation of Morbid Jealousy. Asian J Psychiatr. 2011 Dec; 4(4):258-60.

11. Cipriani G, Vedovello $M$, Nuti A, di Fiorino A. Dangerous passion: Othello syndrome and dementia. Psychiatry Clin Neurosci. 2012 Oct; 66 (6):467-73.

12. Somasundaram O. Facets of morbid jealousy: With an anecdote from a historical Tamil romance. Indian $\mathrm{J}$ Psychiatry. 2010 Jul-Sep; 52(3): 284-288.

13. World Health Organization. The ICD-10 Classification of Mental and Behavioural Disorders: clinical description and diagnostic guidelines. WHO, Geneva 1992

14. Wijesundara H, Dayabandara M, Ellepola A, Hanwella R. Psychopathology in patients with schizophrenia attending a psychiatry outpatient clinic at a tertiary care hospital Sri Lanka Journal of Psychiatry 2011; 2 (1):2327. DOI: http://dx.doi.org/10.4038/sljpsyc.v2i1.3162

15. Hanwella R. Consultation liaison psychiatry in Sri Lanka: a case for sub-specialisation Sri Lanka Journal of Psychiatry 2010; 1 (2):39-41. DOI: 10.4038/sljpsyc. v1i2.2571 